\title{
ANALISIS KEAMANAN WEBSITE SMAN 1 SUMBAWA MENGGUNAKAN METODE VULNERABILITY ASESEMENT
}

\author{
Yudi Mulyanto ${ }^{1}$, Eka Haryanti ${ }^{2 *}$, Jumirah ${ }^{3}$ \\ ${ }_{1,2}$ Teknik Informatika, Universitas Teknologi Sumbawa \\ email: yudi.mulyanto@uts.ac.id ${ }^{1}$, eka.haryanti@uts.ac.id ${ }^{2 *}$,jumirahdewi@gmail.com ${ }^{3}$
}

\begin{abstract}
Abstrak: SMAN 1 Sumbawa merupakan sekolah yang menyediakan informasi kepada siswa-siswi melalui sistem informasi berbasis Website untuk memudahkan pelayanan administrasi sekolah. Mengingat Website dapat diakses secara luas, maka perlu diperhatikan keamanan pada Website. Salah satunya dengan menggunakan metode Vulnerability Asesment. Metode Vulnerability Asesment salah satu metode untuk melakukan pengujian kerentanan pada Website atau aplikasi yang berpotensial masuknya serangan yang terdiri dari beberapa tahapan seperti Network Discovering, Vulnerability Scanning, Resull Analisis. Tahapan ini bertujuan untuk mengidentifikasi celah keamanan pada website SMAN 1 Sumbawa. Pengujian yang telah dilakukan berhasil mengidentifikasi empat tingkat kerentananya yaitu hight, medium, low, dan informational pada Website SMAN 1 Sumbawa. Adapun tingkat kerentanan hight yang didapatkan adalah SQL Injection. Dengan kerentanan $S Q L$ Injection memudahkan penyerang mengakses seluruh database. Hasil pengujian yang telah dilakukan menunjukkan bahwa pada Website SMAN 1 Sumbawa memiliki banyak celah kerentananatau Vulnerability bahwa website SMAN 1 Sumbawa masih dalam keadaan tidak aman.
\end{abstract}

\section{Kata Kunci: Open Web Application Security Project (OWASP), Vulnerability Assessment, Website SMAN 1 Sumbawa}

Abstract: SMAN 1 Sumbawa is a school that provides information to students through a website-based information system to facilitate school administration services. Considering that the Website can be accessed widely, it is necessary to pay attention to its security. One of them is by using the Vulnerability Assessment method. The Vulnerability Assessment method is a method for conducting vulnerability testing on a website or application that can enter an attack which consists of several stages such as Network Discovering, Vulnerability Scanning, and Result Analysis. This stage aims to identify security holes on the SMAN 1 Sumbawa website. The tests carried out have identified four levels of Vulnerability, namely high, medium, low, and informational, on the SMAN 1 Sumbawa website. The hight vulnerability level obtained is SQL Injection. The SQL Injection vulnerability makes it easy for attackers to access the entire database. The tests carried out show that the SMAN 1 Sumbawa Website has many vulnerabilities or Vulnerabilities that the SMAN 1 Sumbawa Website is still in an unsafe state.

Keywords: Open Web Application Security Project (OWASP), Vulnerability Assessment, Website SMAN 1 Sumbawa

\section{PENDAHULUAN}

Perkembangan teknologi saat ini mengalami perubahan yang sangat pesat. Hal ini dapat dilihat dari banyaknya pengguna website yang semakin banyak baik untuk keperluan suatu instansi, pendidikan, organisasi, maupun keperluan pribadi. Keamanan menjadi salah satu aspek penting dalam segala hal.

SMAN 1 Sumbawa yang memanfaatkan kemajuan teknologi dalam menyampaikan informasi dengan menggunakan website. Seiring dengan kemajuan teknologi pentingnya keamanan terhadap suatu website menjadi hal utama karena apabila suatu keamanan diabaikan memungkinkan terjadinya pencurian data atau mengubah tampilan dari sauatu website.

SMAN 1 Sumbawa merupakan salah satu Sekolah Menengah Atas Negeri yang ada di Sumbawa yang telah terakreditasi A, yang berada di jl. Garuda. No. 1, Bugis, Kec Sumbawa, Kab. Sumbawa. Nusa Tenggara Barat. SMAN 1 Sumbawa merupakan sekolah yang menyediakan informasi kepada siswa siswi melalui sistem informasi berbasis web untuk memudahkan pelayanan administrasi sekolah.
Dalam pelayanannya SMAN 1 Sumbawa menyediakan informasi dalam sebuah website https://smanika-sumbawabesar.sch.id. Adapun beberapa tampilan halaman yang ada pada website SMAN 1 Sumbawa yaitu daftar nama guru dan staf, galery sekolah, pengumuman dan berita utama. Beberapa tahun lalu website tersebut pernah diakses oleh orang yang tidak bertanggung jawab dan membuat tampilan dari website tersebut berubah.

Maka dari permasalahan tersebut penulis menawarkan solusi yaitu dengan menganalisa keamanan website menggunakan tool Open Web Aplication Security Project (OWASP). Dalam analisa tersebut akan diperoleh berbagai macam kerentanan yang memungkinkan penyerang masuk dalam website SMAN 1 Sumbawa. Kemudian peneliti akan memberikan rekomendasi dari hasil analisa keamanan website tersebut.

Dengan adanya analisa keamanan website SMAN 1 Sumbawa, diharapkan mampu menjadi solusi bagi SMAN 1 Sumbawa agar dapat meningkatkan keamanan Website. 


\section{TINJAUAN PUSTAKA}

Analisis adalah sebuah kegiatan untuk mencari pola atau atau cara berpikir yang berkaitan dengan pengujian secara sistematis terhadap sesuatu untuk menentukan bagian, hubungan antar bagian, serta hubungan dengan keseluruhan

Analisis adalah suatu usaha untuk menguraikan suatu masalah menjadi bagian-bagian (decomposition) sehingga susunan bentuk sesuatu yang diuraikan itu tampak dengan jelas sehingga dapatdimengerti permasalahannya . Analisis data adalah proses mencari dan menyusun secara sistematis data yang diperoleh dari hasil wawancara, catatan lapanngan, dan dokumentasi, dengan cara mengorganisasi data kedalam kategori, menjabarkan kedalam unit-unit melakukan sintesa, memilih mana yang penting dan yang akan dipelajari, dan membuat kesimpulan sehingga mudah dipahami oleh diri sendiri maupun orang lain

Website merupakan kumpulan halaman halaman yang digunakan untuk menampilkan informasi teks, gamabar, diam atau gerak, animasi, suara, atau gabungan dari semuanya, baik yang bersifat statis atau dinamis yang membentuk sutu rangkaian bangunan yang saling terkait, yang masing masing dihubungkan dengan jaringan jaringan halaman

website (lebih dikenal dengan sebutan situs) adalah sejumlah halaman web yang memiliki topik saling terkait, terkadang disertai pula dengan berkas berkas gambar, video atau jenis jenis berkas lainya

Keamanan suatu website merupakan salah satu prioritas yang sangat utama bagi seorang pengololah atau pengguna situs. Kebanyakan pengguna hanya mengutamakan design tampilan dan konten apa supaya menarik pengunjung sebanyak banyaknya. Jika seorang pengolah atau pengguna mengabaikan keamanan suatu website maka yang dirugikan adalah pengguna itu sendiri karena seseorang dapat mengambil data-data penting pada suatu website dan bahkan pula dapat dapat mengacak-acak tampilan website tersebut. Paling utama keamanan sebuah situs adalah melindungi komputer, aplikasi dan jaringannya dengan tujuan mengamankan informasi yang berada didalamnya

Vulnerability Asesment merupakan kerangka kerja konseptual menyeluruh yang pilih, termasuk definisi kerentanan yang menentukan risiko untuk pengukuran. Hal ini juga tergantung pada tujuan pengguna hasil penilaian, yang dapat berkisar dari niat untuk menginformasikan kebijakan internasional atau untuk mengacu tindakan ditingkat masyarakat

Vulnerability Asesment adalah melakukan identifikasi Vulnerability dari suatu aplikasi sistem operasi dan infrastruktur jaringan. Vulnerability Asesmen tidak melakukan celah atau kelemahan dari suatu sistem. Sedangkan Vulnerability adalah suatu kelemahan dalam desain sistem implementasi sistem atau operasi dan manajemen yang dapat dimanfaatkan untuk melanggar kebijakan keamanan sistem. Vulnerability Asesement lebih fokus untuk menemukan beragam public Vulnerability pada seluruh sistem komputer dalam jaringan target

Menurut (Digdo, 2017) sebagian orang selalu mengaitkan antara metode Penetration Testing dengan metode Vulnerability Asesment. Adapun perbedaan antara Metode Penetration Testing dengan Metode Vulnerability Asesment, ditunjukkan pada tabel berikut

Tabel 1. Perbedaan Metode Penetration Testing dan Vunerability Asessment

\begin{tabular}{lll}
\hline NO & $\begin{array}{l}\text { Metode } \\
\text { Penetration } \\
\text { Testing }\end{array}$ & $\begin{array}{l}\text { Metode } \\
\text { Vulnerability } \\
\text { Asesment }\end{array}$ \\
\hline 1 & Identifikasi & Identifikasi \\
& Beberapa & semua Celah \\
& Celah & Keamanan \\
& Keamanan & \\
& Pendekatan & Pendekatan \\
2 & risiko IT & Bisnis dan \\
& Pesiko IT & Pendekatan \\
3 & Secara Teknis & secara Teori
\end{tabular}

Open Web Aplication Security project (OWASP) adalah sebuah organisasi internasioanal yang bersifat non-profit, didirikan oleh Open Web Aplication Security Project (OWASP) foundation pada 21 April 2004 diAmerika serikat. Open Web Aplication Security Project (OWASP) fokus pada peningkatan keamanan perangkat lunak dan didedikasikan untuk memungkinkan organisasi dalam mengembangkan, memperoleh, mengoprasikan dan memelihara aplikasi terpercaya untuk menjamin keamanan yang dibuat atau dikembangkan. Open Web Aplication Security Project (OWASP) memeliki misi untuk mengamankan sofware sehingga orang-orang dan organisasi dapat membuat keputusan terhadap resiko keamanan yang benar

Network Mapper (NMAP) merupakan alat pemetaan yang berfungsi memindai jaringan dan mengintegrasikan perangkat yang diidentifikasi secara langsung dalam diagram dan peta jaringan atau sering disebut Automatic Mapper (yang menghasilkan peta jaringan secara otomatis). Solusi pemetaan jaringan terintegrasi jelas lebih unggul daripada kombinasi pemindai jaringan dan alat pemetaan dalam hal kegunaan, tetapi peta yang dibuat secara otomatis seringkali tidak kekurangan dalam hal keterbacaan: banyaknya perangkat jaringan 
dan koneksi membingungkan kejelasan hasil alih-alih menghasilkan gambaran yang jelas

Who.is merupakan sebuah protokol yang memungkinkan kita untuk mengakses database sebuah domain. Dengan Who.is anda bisa mengetahui pemilik sebuah Website, informasi, kontak, server DNS, kapan mulai beroperasi, dan informasi lainnya. Secara garis besar, port dibagi menjadi dua bagian, yang pertama port fisik (physical port) yang merupakan port dibagian belakang CPU, seperti port serial, dan port monitor. Lalu ada pula port perangkat lunak (software port) merupakan port yang digunakan oleh softwarel. untuk melakukan koneksi dengan komputer lain. Ada banyak port yang terdapat pada sebuah komputer, apalagi sewaktu terhubung dengan internet. Beberapa port yang umum adalah adalah port 80 (HTTP), yaitu port untuk membuka halaman Website, port 20 (HTP), untuk melakukan upload maupun dawnload file, port 110 (POP3) untuk menerima email, serta masih banyak port lainny. Nskloop (Name Server Lookup)merupakan sebuah DNS query tool yang bisa digunakan untuk konversi dari nama domain menjadi IP Address maupun sebaiknya. Serta untuk mengetahui DNS record.

Nslookup (Name Server Lookup) dapat dijalankan dalam dua modus : interaktif dan non interaktif. Modus non interaktif berguna bila ada satu bagian data yang perlu dikembalikan. Bila perintah ini dijalanakan tanpa menggunakan parameter, akan menampilkan informasi default, server serta address dari koneksi jaringan kita saat ini

\section{METODE PENELITIAN}

Dalam melakukan penelitian di SMAN 1 Sumbawa dengan judul Analisis Keamanan Website SMAN 1 Sumbawa Menggunakan Metode Vulnerability Asesment.

Adapun tahapan - tahapan yang akan dilakukan pada penelitian ini adalah sebagai berikut :

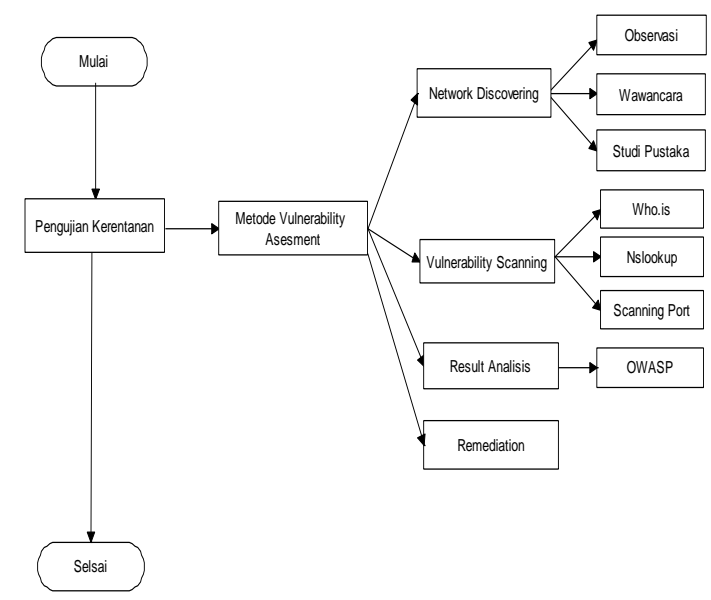

\section{Metode Vulnerability Asesment}

Vulnerability Asesment atau penilain kerentanan yaitu metode yang digunakan untuk melakukan pengujian pada poin yang berpotensial masuknya serangan pada website SMAN 1 Sumbawa.

Ada beberapa langkah dalam melakukan analisis kerentanan menggunakan metode Vulnerability Asesment :

\section{Network Discovery}

Tahap ini bertujuan untuk menemukan struktur rancang bangun dari keamanan jaringan pada target sasaran halaman website yanng dituju. Adapun barometer pada Network discovery.

\section{Observasi}

Pada metode ini peneliti melakukan survei lokasi untuk mendapatkan hasil yang lebih valid dan nantinya menjadi gambaran dasar untuk masuk ke tahap berikutnya.

\section{Wawancara}

Pada penelitian ini peneliti melakukan wawancara dengan mengajukan beberapa pertanyaan untuk mendapatkan informasi yang dibutuhkan dengan cara tatap muka bersama kepala humas SMAN 1 Sumbawa.

\section{Studi Pustaka}

Pada tahap ini peneliti mempelajari konsep, teknk, maupun informasi dari berbagai sumber seperti internet, buku, jurnal, maupun artikel ilmiah lainnya yang berkaitan dengan jaringan komputer.

\section{Vulnerability Scanning}

1) Who. is

Who.is bertujuan untuk mendapakan informasi mengenai sebuah domain, alamat, No. telepon, alamat emil, kapan domain didaftarkan dan kapan domain itu akan kaduluarsa.

2) Nslookup

Nslookup Yang bertujuan mengetahui IP dari sebuah domain.

3) Scanning port

Scaning Port Bertujuan untuk menyelidiki server atau host port terbuka.

\section{Result Analisis}

Tahap ini bertujuan untuk mencari celah kerentanan atau Vulnerability pada website SMAN 1 Sumbawa dengan menggunakan tool Open Web Aplication Security Project (OWASP), yang mencangkup beberapa celah keamanan seperti SQL injection, CrossDomain Java Scrip Source File Inclusion 


\section{Remediation}

Tahap ini bertujuan untuk megurangi resiko kerentanan pada suatu website. Tahap ini merupakan kesimpulan akhir, berupa tabel dari jumlah nilai dari sebuah penelitian yang telah dilakukan Penulis melakukan penelitian pada website SMAN 1 Sumbawa.

\section{HASIL DAN PEMBAHASAN}

\section{Implementasi}

Pengecekan halaman Website

a. Who.is

Untuk mengambil informasi sebuah alamat domain dari website SMAN 1 Sumbawa, maka penulis menggunakan website Who.is. Adapun hasil informasi domain yang didapatkan yaitu https://smanika-sumbawa besar.sch.id

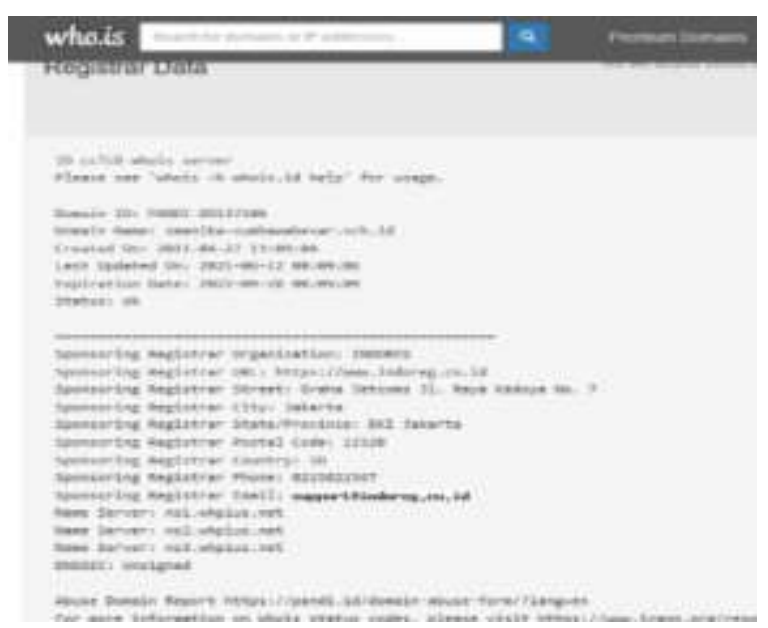

Gambar 2. Hasil Pengecekan Website SMAN 1 Sumbawa

Berdasarka gambar diatas Hasil dari pengambilan informasi domain dari website SMAN 1 Sumbawa menggunakan who.is terhadap target domain yang telah ditentukan didaptkan berbagai informasi terkait pendaftaran nama domain masa berlakunya serta Domain Name System (DNS) server yang digunakan.

\section{b. Nslookup}

Untuk mengetahui IP dari sebuah domain pada website SMAN 1 Sumbawa.

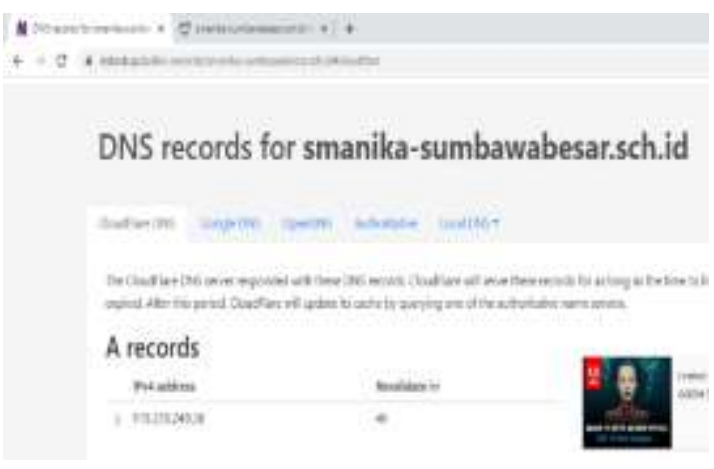

Gambar 3. Hasil Scanning dengan tool Nslookup

Berdasarkan pengujian port scaning diatas, dapat terlihat alamat website dan IP adress pada website SMAN 1 Sumbawa. Adapun hasil Scanning oleh tool Nslookup pada website SMAN 1 Sumbawa menampilkan informasi IP yaitu "119.235.249.36"

\section{c. Scanning Port}

Untuk melihat server atau port terbuka pada SMAN 1 Sumbawa penulis menggunakan tool Network Mapper (NMAP). Adapun hasil dari pengujian menggunakan tool (Network Mapper) NMAP dengan port Scanning sebagai berikut.

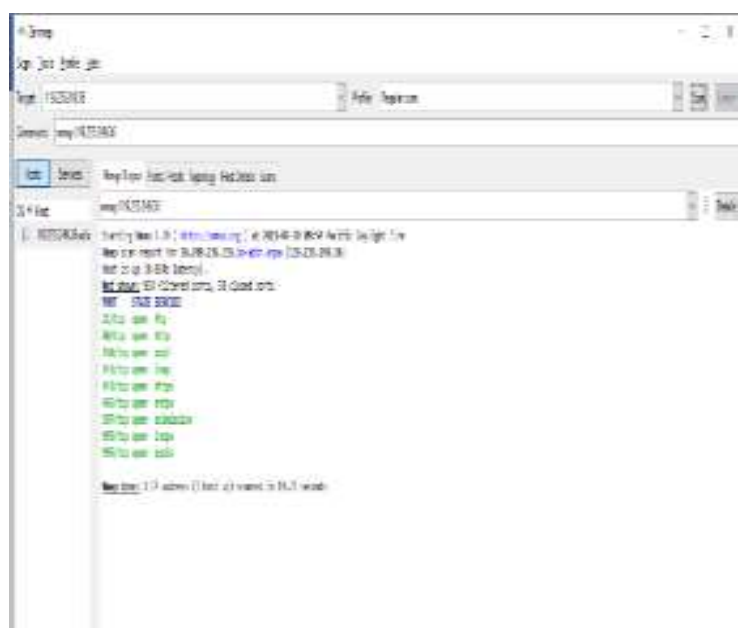

Gambar 4. Hasil Port Scanning dengan Tool Nmap

Berdasarkan pengujian port scaning diatas dapat terlihat port Service seperti ftp, http, pop3, imap, https, smtps, submission, imaps, dan pop3s yang statusya terbuka.

\section{Pengujian Kerentanan}

Vunerability Scannin guntuk mencari celah kerentanan keamanan pada Website SMAN 1 Sumbawa penulis menggunakan tool Open Web Aplication Security Project (OWASP). Berikut tampilan pengujian kerentanan keamanan Website yang telah dilakukan oleh penlis. 


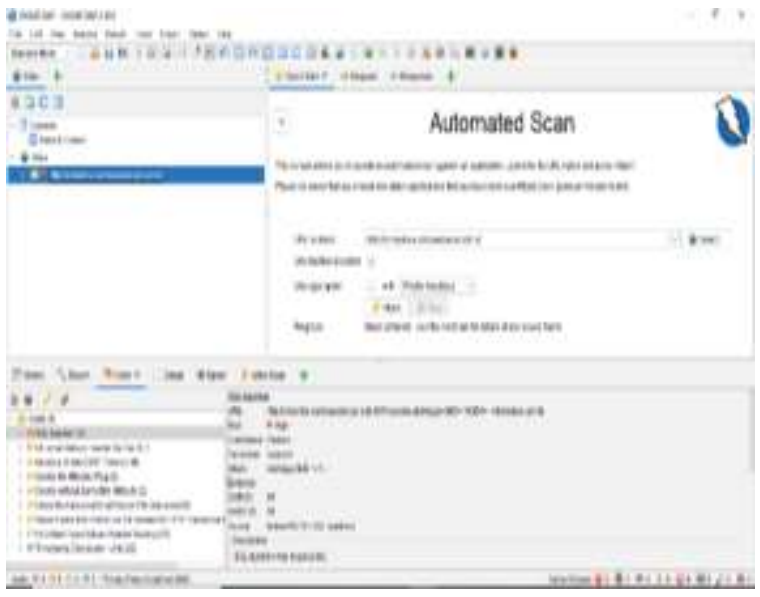

ringan

\section{Gambar 5. Hasil Analisis Kerentanan Tool OWASP}

Berdasarkan hasil pengujian yang dilakukan pada tool Open Web Aplication Security Project (OWASP), didapatkan beberapa celah keamana yang ada di Website SMAN Sumbawa diantaranya berupa : SQL Injection, X-Frame Options Header Not Set, Absence of Anti-CSRF Tokens, Cookie No flag, Cookie Without Same Site Attribute, Cross-Domain Java Script Source File Inclusio, Server Leaks Information via” X-By "HTTP Response Header Field (s), Timestamp Disclosure-Uni.

\section{Penilaian Kerentanan}

Berikut hasil dari pengujian kerentanan keamanan Website SMAN 1 Sumbawa dapat dilihat pada tebael berikut

Tabel 2. Tabel Pengujian Kerentanan

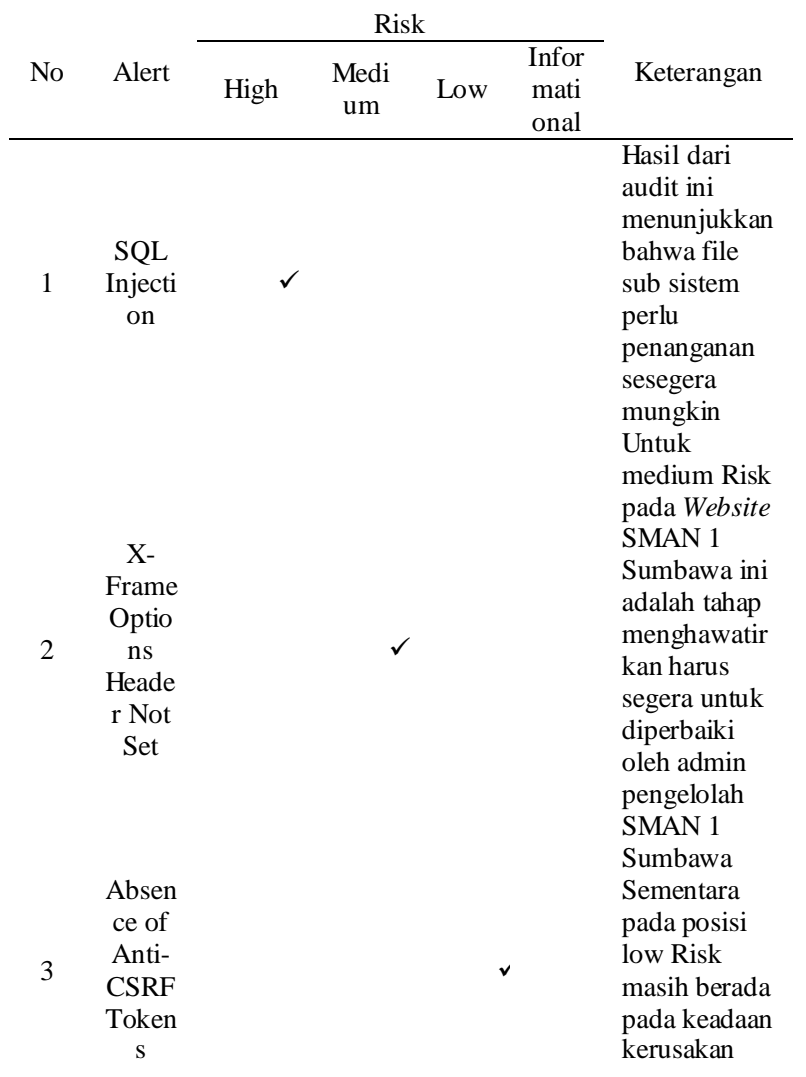

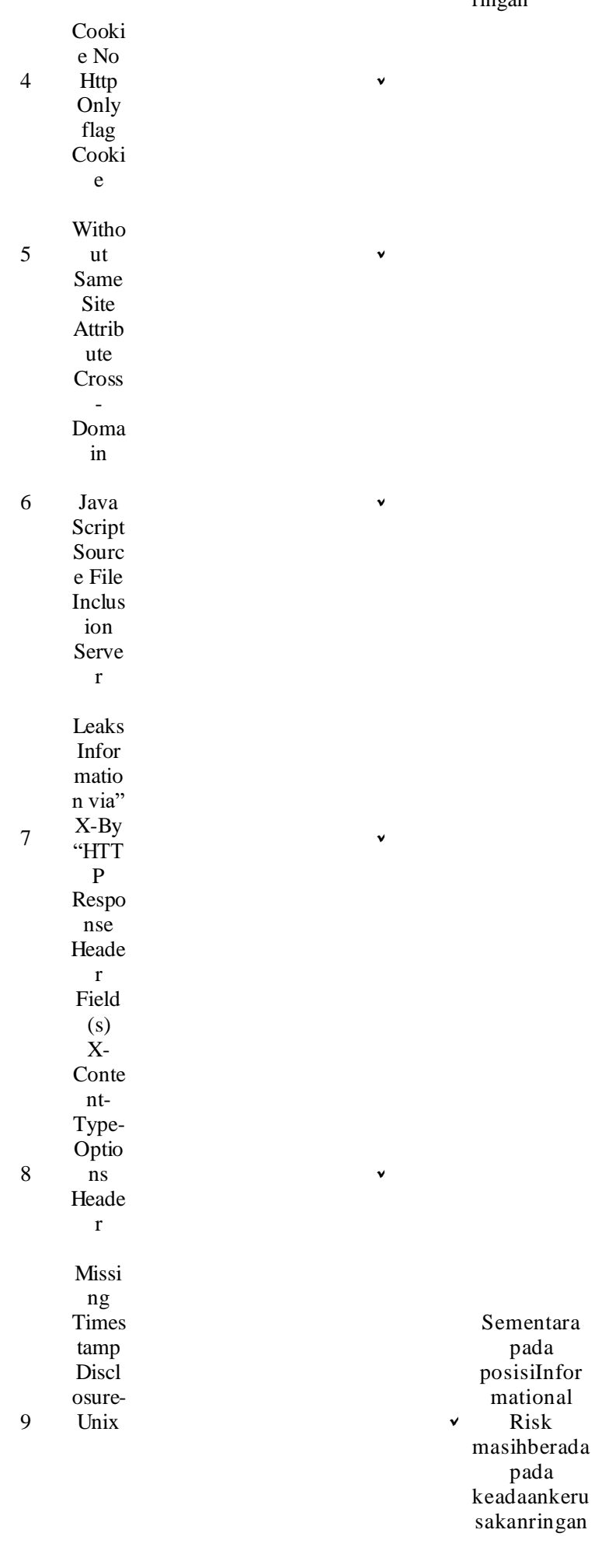

\section{Hasil dan Rekomendasi}

Berikut sebuah saran yang

direkomendasikan oleh tool Open Web Aplication Security Project (OWASP). 
Tabel 3. Rekomenasi Oleh Tool OWAPS

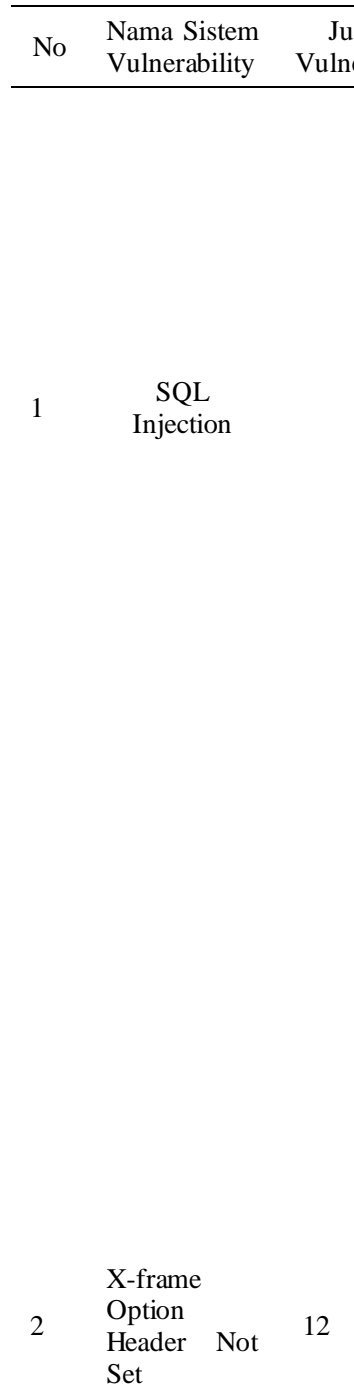

\footnotetext{
Absence Of

Tokens
}

3 Anti CSRF 7

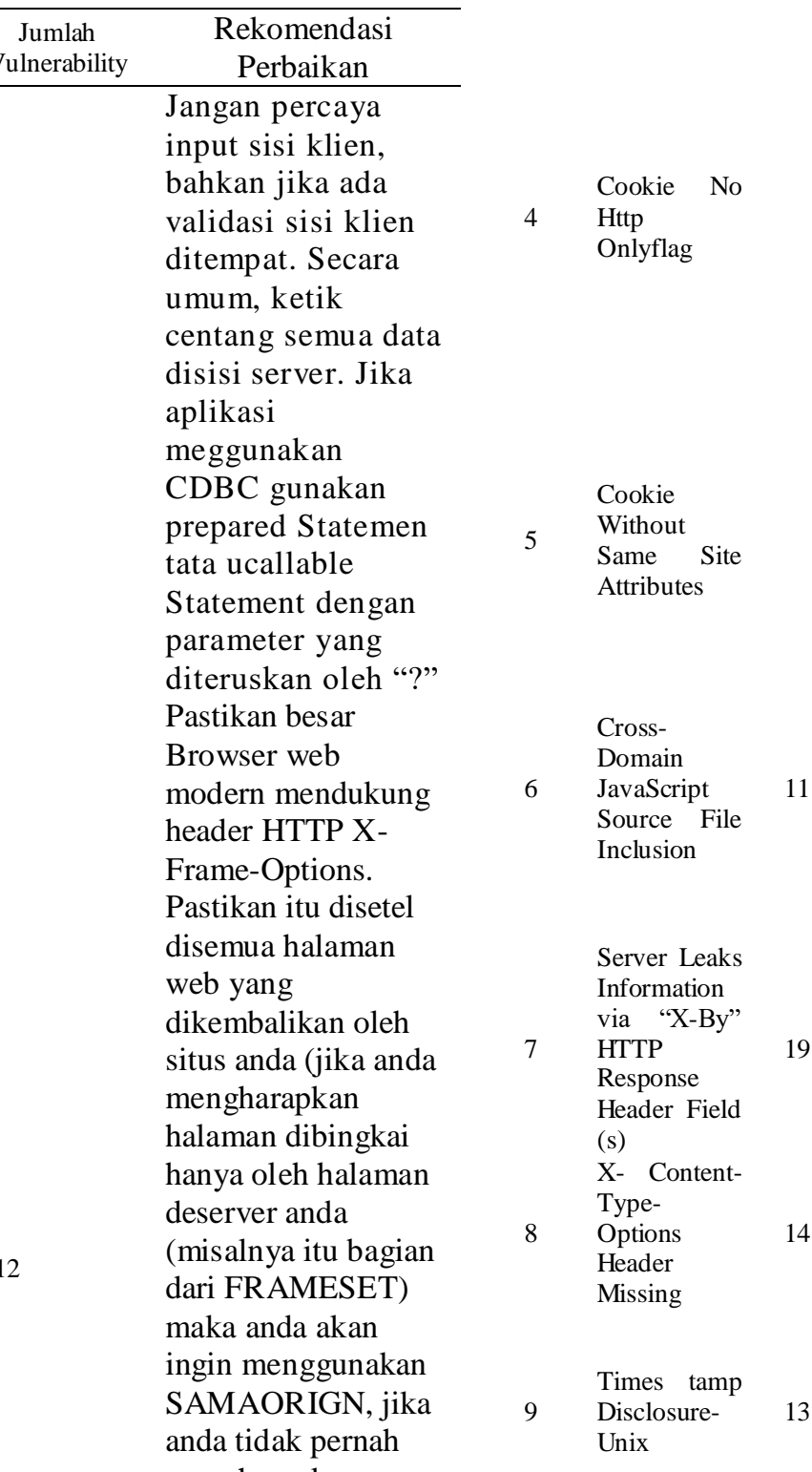

mengharapkan

halaman untuk

dibingkai, anda

harus menggunakan

DENY, atau

pertimbangan untuk

menerapakan arahan

"frame-ancestors"

kebijakan keamanan

konten

Arsitektur dan desain. Diperiksa menggunakan perpustakaan atau kerangka yang tidak memungkinkan.

Kelemahan ini

terjadi atau

menyediakan

kontruksi yang

membuat kelemahan

ini mudah untuk menghindari

Pastikan bahwa

aplikasi atau server

Web menyetel

header Content-

Type options ke

'nosniff' untuk

semua halaman Web

jika memungkinkan,

pastikan bahwa

penggunaan

browser Web

Standar-Compliant

Pastikan atribut

Same Site diatur

ke'lax' atau

idealnya 'strice' untuk semua cookie Pastikan file sumber java Script dimuat hanya dari sumber terpercaya dan sumber tidak dapat dikontrol oleh penggunan khir aplikasi

Pastikan server web anda, server alikasi, penyimbang beban, dll. Dikonfigurasikan untuk menekan header

\section{KESIMPULAN DAN SARAN}

Kesimpulan

Berdasarkan pengujian dan analisis keamanan website SMAN 1 Sumbawa dapat disimpulkan bahwa website SMAN 1 Sumbawa memiliki banyak celah kerentanan yang dibuktikan dengan pengujian kerentanan menggunakan Open Web Aplication Security Project (OWASP) dari hasil pengujian yang dilakukan ditemukan beberapa kerentanan salah satunya SQL Injection dimana kerentanan tersebut memudahkan penyerang mengakses seluruh database. Adapun rekomendasi penanganan SQL Injection yaitu mengimplementasikan algorita kriptografi untuk melindungi username dan pasword pengguna.

Saran

Berdasarkan hasil penelitian ini masih memiliki beberapa kekurangan yakni metode yang 
digunakan oleh penulis tidak melakukan perbaikan langsung kedalam sistem untuk penelitian selanjutnya dapat menggunakan metode lain untuk melakukan perbaikan langsung kedalam sistem.

\section{DAFTAR PUSTAKA}

[1] Bartley, D. A. (1979). Study of children's respiratory illnesses. Bulletin of the International Union against Tuberculosis, 54(2), 211-214.

[2] Bekti, bintu humairah. (2015). Mahir Membuat Website Dengan Adobe Dreamweaver CS6. CSS dan JQuery. Yogyakarta: Andi.

[3] Digdo, G. P. (2017). Panduan Audit keamanan Komputer Bagi Pemula. PT. Elex Media Komputindo. Jakarta.

[4] Guntoro, G., Costaner, L., \& Musfawati, M. (2020). Analisis Keamanan Web Server Open Journal System (Ojs) Menggunakan Metode Issaf Dan Owasp (Studi Kasus Ojs Universitas Lancang Kuning). JIPI (Jurnal Ilmiah Penelitian Dan Pembelajaran Informatika), 5(1), 45. https://doi.org/10.29100/jipi.v5i1.1565

[5] Ika yusnita sari, Muttaqin Muttaqin, J. J. (2020). keamanan data dan informasi. Yayasan Kita Menulis.

[6] Orisa Mira, \& Ardita, M. (2021). Vulnerability Assesment Untuk Meningkatkan Kualitas Kemanan Web. Jurnal Mnemonic, 4(1), 16-19. https://doi.org/10.36040/mnemonic.v4i1.3213

[7] Rahmadi, M. luthf. (2013). Tips Membuat Website tanpa Coding \& Langsung Online.

[8] Riadi, I., Yudhana, A., \& W, Y. (2020). Analisis Keamanan Website Open Journal System Menggunakan Metode Vulnerability Assessment. Jurnal Teknologi Informasi Dan Ilmu Komputer, 7(4), 853. https://doi.org/10.25126/jtiik.2020701928

[9] Satori, A. komariah dan D. (2014). Metodelogi
Penelitian Kualitatif. Bandung: Alfabetha.

[11] Senekal, F. P., \& Vorster, J. S. (2007). Network Mapping and Usage Determination. Military Information Communications Simposium South Africa, August 13. https://www.researchgate.net/publication/30511385_ Network_mapping_and_usage_determination

[12] Sugiyono. (2015). Metode Penelitian Kombinasi (Mix Methods). Bandung: alfabetha.

[13] Suharsaputra, U. (2012). Metode Penelitian Kuantitatif, Kualitatif, dan Tindakan. Bandung, Refika Aditama.

[14] Utoro, S., Nugroho, B. A., Meinawati, M., \& Widianto, S. R. (2020). Analisis Keamanan Website E-Learning SMKN 1 Cibatu Menggunakan Metode Penetration Testing Execution Standard. Multinetics, 6(2), 169-178. https://doi.org/10.32722/multinetics.v6i2.3432

[15] Yayasan OWAPS. (2010). Versi Indonesia.

[16] Zam, E. (2011). Sakti Hacker. jakarta, Mediakita. 